\title{
Marco Jaff From the Vault of the Heavens
}

A hypothesis regarding Filippo Brunelleschi's invention of linear perspective and the costruzione legittima

Many clues lead to the conjecture that Brunelleschi knew about the use of the astrolabe, an instrument very often used in his times; among his friendships we find the astronomer Paolo Dal Pozzo and engineer Mariano di Jacopo da Siena, who certainly knew how to use the astrolabe accurately. Because this instrument is based on the principle of stereographic projection, a particular kind of central projection, it is quite possible that Filippo applied this principle for the perspective construction outline for Masaccio's Trinità in S. Maria Novella, as well as for the two lost panels of the Baptistery of Florence.

\section{Introduction}

It is very unlikely that by 1401 , when Filippo Brunelleschi sculpted the panel for the Florentine Baptistery competition, he had elaborated any theory of linear perspective. ${ }^{1}$ The scene of the sacrifice of Isaac is composed with a great sense of drama, and the strong, precise figures are barely contained by the lunettes of the frame (Fig. 1). As Eugenio Battisti has noted,

the space of his panel is still ingenuous, it is the prehistory of those perspectival studies for which he became famous; the sacrificial altar (...) is still conceived and constructed according to the visual sensibility of the early trecento, and the overall spatial articulation seems to be undergoing a three-dimensional revival of Giottoesque space [Battisti 1976:24].

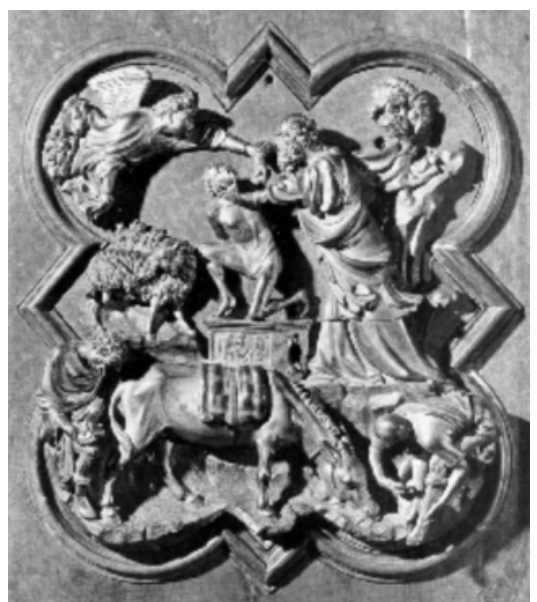

Fig. 1. Filippo Brunelleschi, Panel for the Baptistery of Florence, Sacrifice of Isaac, 1401 
Almost twenty-five years later, Filippo projects for his friend Masaccio the architecture of the Holy Trinity (Trinità) at S. Maria Novella ${ }^{2}$, and in order to construct the image of this invented space, he employs the technique of perspective, of which he shows a mature mastery. From what source, during those twenty-five years, did he draw the knowledge that allowed him to develop such a precise and revolutionary theory of perspectiva artificialis?

The hypothesis I will seek to prove, and which was not explored in much depth by the recent exhibition at the Uffizi, The invention of perspective [Camerota 2001], is that this knowledge was derived by Brunelleschi from the principles that govern the working of the astrolabe (Fig. 2), an instrument created for the observation of the stars but used as well for land measurement. As we shall see, in all probability Brunelleschi knew and used the astrolabe, which is based on a particular type of what we now call stereographic projections. $^{3}$

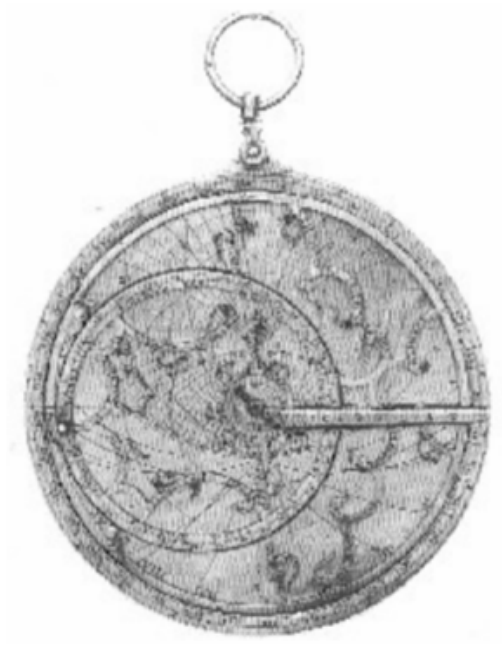

Fig. 2. The astrolabe

\section{Brunelleschi and Early Perspective Theory}

Much discussion is still devoted to whether perspective was known in classical antiquity. ${ }^{4}$ It is fair to say that much certainty on the matter has not yet been attained. But in view of the fact that perspective was empirically employed, especially in Roman wall painting of the first Century A.D., one might presume that a theoretical knowledge was also widespread. In the following centuries, however, although there is no lack of examples of perspectively realistic representation (for example Giotto's work at the Cappella degli Scrovegni), that knowledge was lost: we can therefore regard as historically accurate the statement that, until Brunelleschi, no one in the early quattrocento had a thorough knowledge of the theory of perspective. 
It should be observed on the other hand that the Middle Ages did not constitute a complete break with the culture of antiquity; rather, the essence of Humanism consists more of a new attitude of critical understanding with respect to antiquity, than the rediscovery of the classical texts (cfr. [Garin 1964: 18]. Brunelleschi himself turns to classical antiquity not so much "to bring back to light the ancient charm of the lost and extinguished style", as Leonardo Bruni said of Petrarch, ${ }^{5}$ but above all because from that study he could draw inspiration to stimulate and nourish a new conception of architecture and figurative art. Testimony to that, if nothing else, are his trips to Rome to draw the ancient ruins. ${ }^{6}$ And even the discovery of perspective can be attributed in part to this attitude, and more precisely to the critical reflection on Ptolemaic theory and methods handed down from antiquity regarding the observation of the stars, and consequently also the use of the astrolabe, their main instrument (Fig. 3).

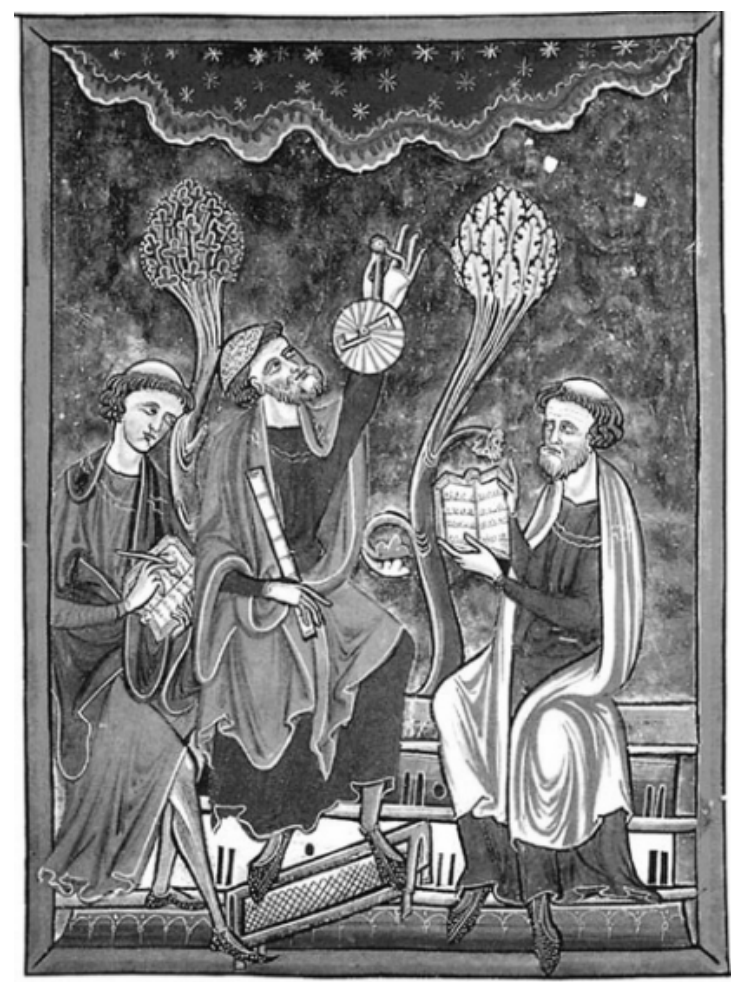

Fig. 3. Observations with an astrolabe in thirteenth-century France

As to whether Brunelleschi knew the astrolabe and its theory, rather than proof, there are clues which, taken all together give a very convincing quadro probatorio. The first clue is this: right at the beginning of the quattrocento, in that climate of reappraisal of the ancient authors mentioned above, Manuel Chrisoloras and Agnolo da Scarperia brought to Florence a copy of Ptolemy's Geografia, and a short time after they began to circulate a translation. ${ }^{7}$ In the book are described three types of cartographic projection, ${ }^{8}$ 
the third type being the projection system probably developed by Hipparchus in the second century B.C. and which constituted the basis for drawing maps of the sky, and the working of the astrolabe. Given the importance and fame of that book it is highly probable that Filippo would have come to know of it.

A second clue is the friendship between Brunelleschi and the astronomer Paolo Dal Pozzo Toscanelli, who from 1425 helped him in the task of vaulting the dome of S. Maria del Fiore and who, later, built its great sundial. ${ }^{9}$ Certainly Toscanelli would have made regular use of the astrolabe and, since this was his only instrument of observation, it seems entirely credible that he would have discussed it with Filippo.

The third clue is a figure in the De ingeneis (1432-35) by Sienese Mariano di Jacopo (known as "il Taccola"), which represents an engineer measuring the change in level between a water course and its source (Fig. 4, Fig. 5, and Fig. 6). Filippo knew Taccola, whom he probably met in Siena in 1433, and with whom he discussed the occupation of the architect [Battisti 1976: 20]. A few years earlier in 1430, during the siege of Lucca, Filippo acted as military surveyor for the Florentines and was charged with the task of diverting the waters of the Serchio in order to flood the city [Cfr. Galluzzi 1996: 18]. In fact, it has been suggested that the illustration of the De ingeneis may depict Filippo himself intent upon that very task [Fondelli 1977-a: 10]. Although this hypothesis lacks any documentary basis, it does appear incredible that Taccola could have known the astrolabe while Brunelleschi, so much more famous than him, might not.

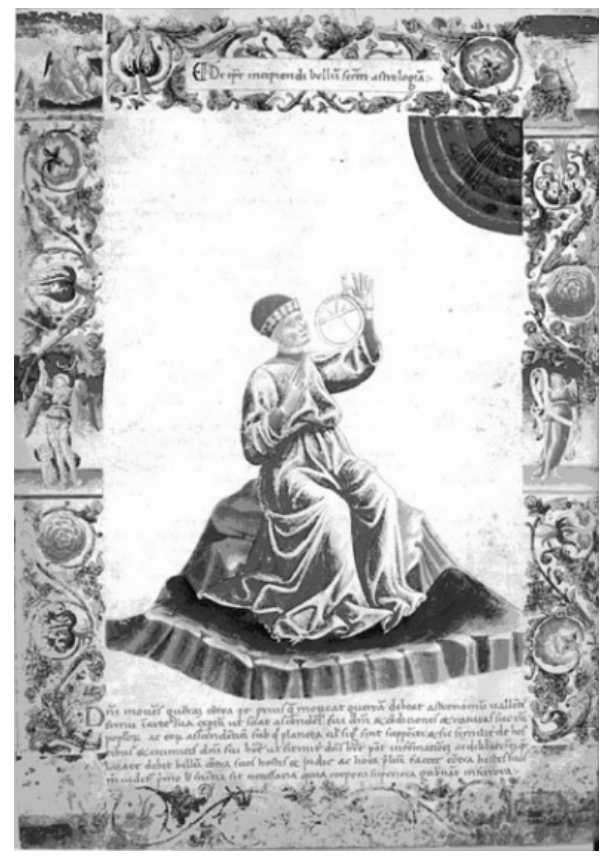

Fig. 4. P. Santini (da Taccola, De machines), c. 6v., Ms. Lat. 7239, De tempore incipiendi bellum secundum astrologiam 


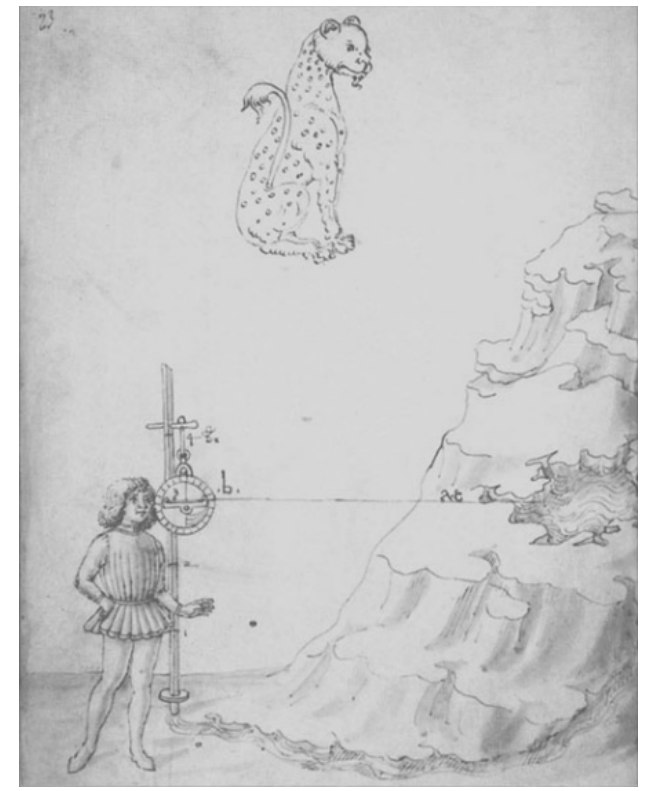

Fig. 5. Anonymous (da Taccola). Measurement of levels with an astrolabe. Ms. Palatino 767 (BNCF), p. 23

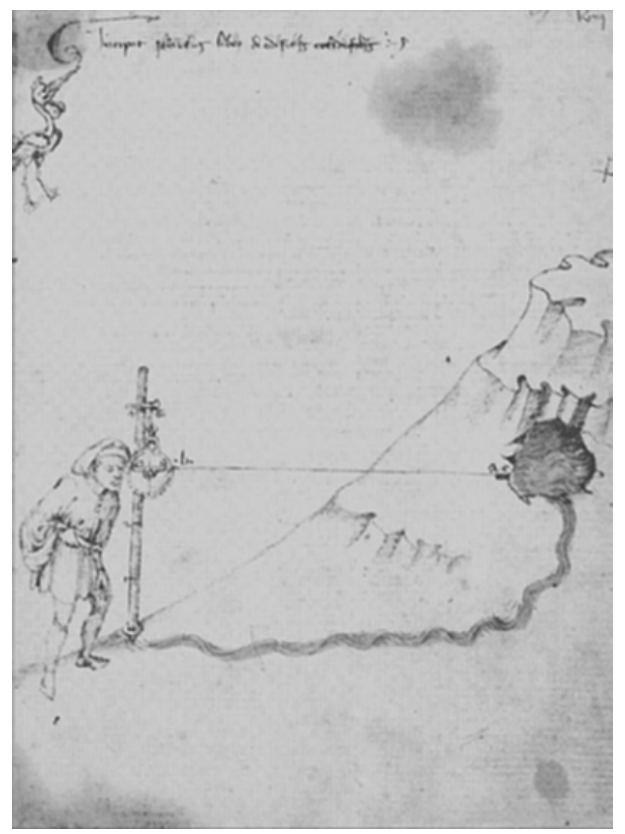

Fig. 6. Use of the astrolabe in the measuremnt of levels from De ingeneis, books III and IV by Mariano di Jacopo (il Taccola), fifteenth century (BNCF, Pal., 766, c. 31) 
The last conjecture is found in Vasari's Lives, where he says that Filippo "by his own hand made some very good and beautiful clocks" [Vasari 1985: 328]. It is quite likely that anyone knowing the workings of mechanical clocks would also understand astronomical clocks such as the astrolabe. In any case, the spread of this instrument from 1300 throughout the West is well documented.

The structure of the Ptolemaic system was thoroughly familiar to Brunelleschi; the Divine Comedy, for instance, which is completely permeated by that system, was extremely popular in his time. It is therefore perfectly reasonable to maintain that Filippo was not only aware of the use of the astrolabe, but also of how to build it, and that consequently he would be in a position to put its principles to use in other applications.

Nevertheless the whole of Western culture remained anchored in the geocentric system developed by the Greeks, amongst others by Hipparchus who in the second century B.C., as we have noted, was also the probable inventor of the astrolabe and of stereographic projections, as indicated by Vitruvius ${ }^{10}$ and above all Ptolemy. ${ }^{11}$ Though during the Middle Ages this whole system of knowledge became weaker, it was not lost altogether and in the West was newly disseminated by Scholasticism and St. Thomas Aquinas (1226-1274), and in the Arab world by Averrhoës (1126-1198) (Fig. 7 and Fig. $8)$.

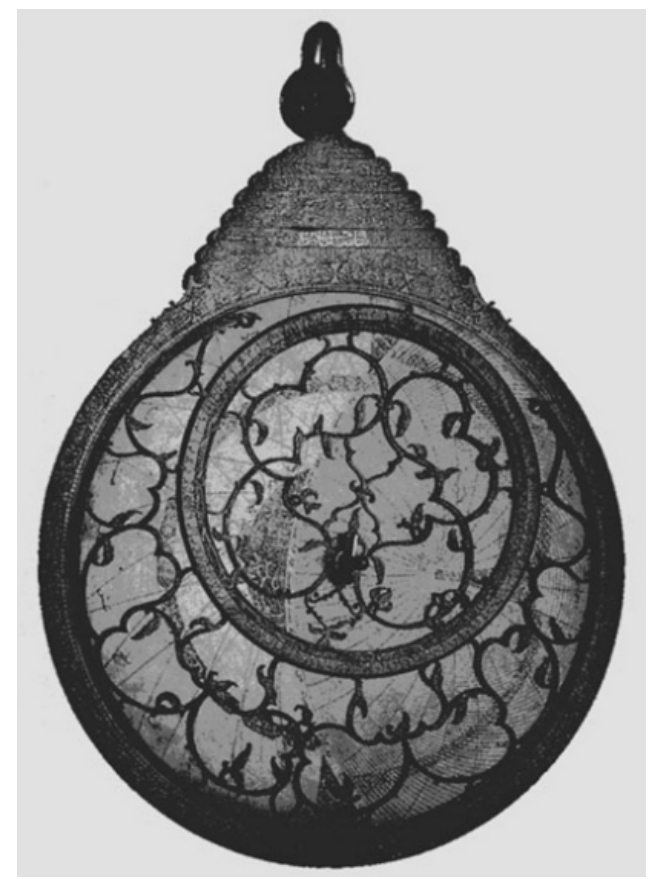

Fig. 7. Astrolabe with seven plates for latitude, made in Isfahan by Abd al-'Ali e Muhammad Baqir in 1124 (= 1712 A.D.) for the Savafid Shah Husayn (British Museum, OA + 369) 


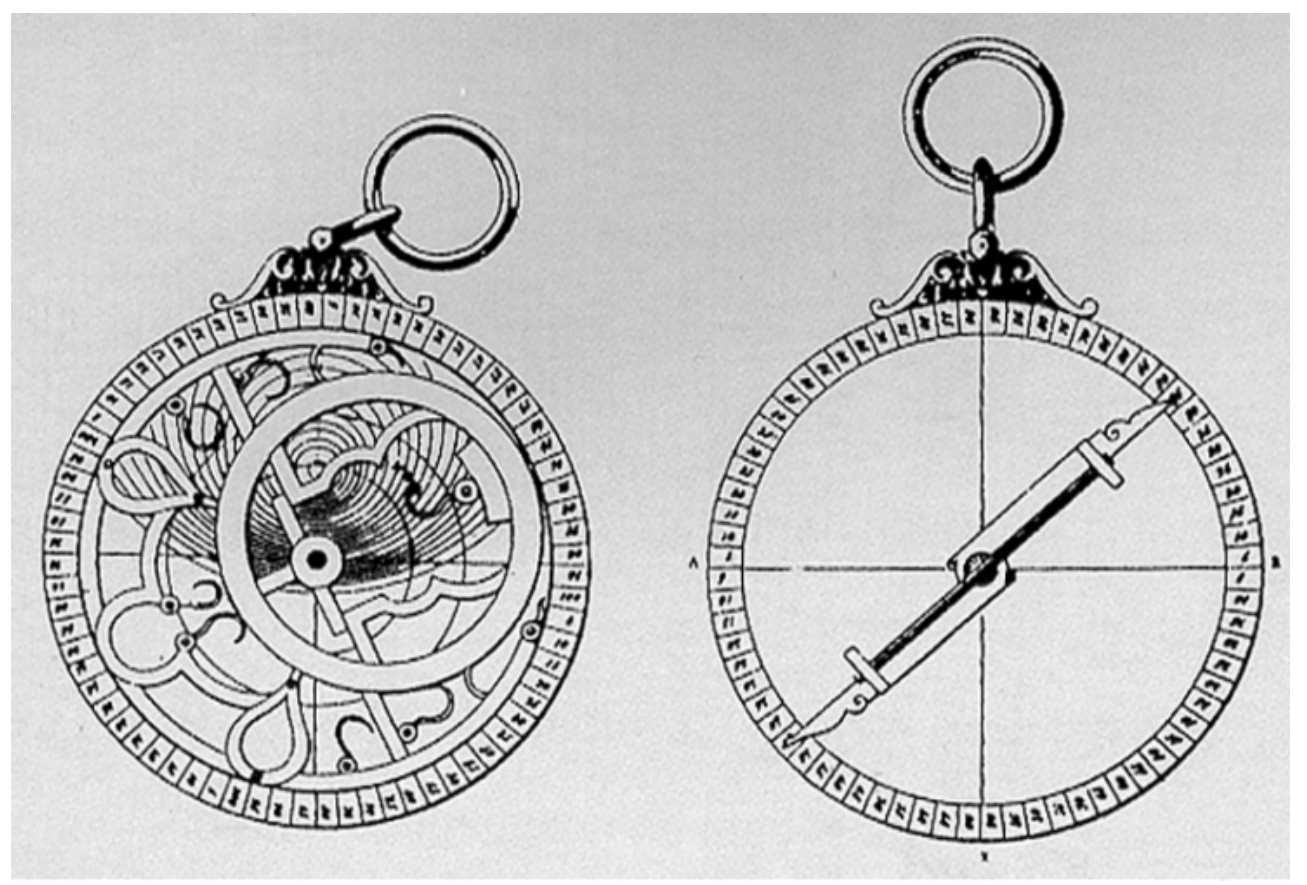

Fig 8. Arab astrolabe of 1200

\section{Projections and the Astrolabe}

We shall now examine the particular type of projections known as stereographic, and what they consist of, taking note of the important similarities they share with linear perspective.

Given a sphere, a point $S$ on its surface is taken as centre of projection, and an equatorial plane not passing through $S$ as projection plane, stereographic projections are those projections on the plane of all the points of the hemisphere that does not contain $S .12$ If we take as an example the terrestrial globe and choose as our centre of projection the South Pole, and as projection plane the plane of the equator, we can project (represent) on that plane all the points of the southern hemisphere (see Fig. 9 and Fig. 10). The same operation can be applied to the celestial sphere, choosing the South Pole and Equator of the Universe. These projections are not very useful for obtaining maps of the Earth because they produce very "distorted" representations, yet they are of great interest in the representation of the celestial sphere precisely because they make it easy to draw upon a plane.

All the processes involved in drawing it are eased by an interesting property: the circles on the sphere (and the movement of the stars in the Ptolemaic model) are transformed into further circles on the projection plane. Also, a reference system consisting of celestial parallels and meridians based on the vertical of the observer, given that it is made up of circles, is easily represented on the plane as a grid of as many circles. ${ }^{13}$ 

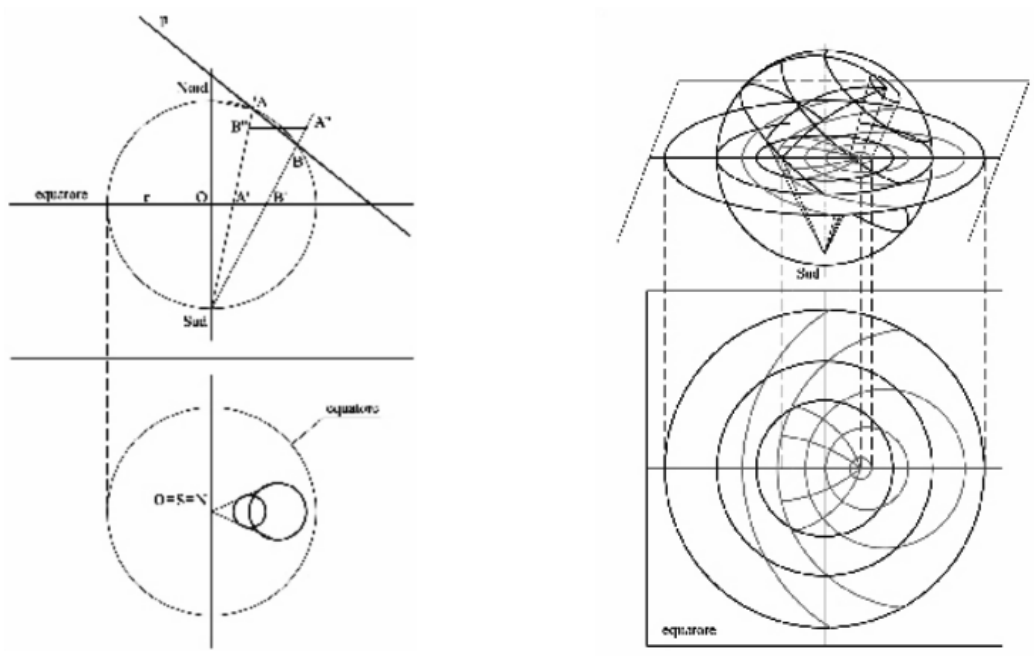

Fig 9 (left) Stereographic projections; Fig. 10 (right) Projection of the meridians and parallels

At this point it is convenient to have a better understanding of the astrolabe: how it is made and what it is for. In essence, the astrolabe is a model of the celestial vault primarily for the measuring of sidereal time. It is composed of many disks superimposed on a "mother" disk which rotate independently over each other: on the back there is normally a scale in degrees, a sight, and often at later dates, a geometric quadrant to measure the angles, altitudes and distances. On the front, on top of the "mother" is found the socalled "tympanum" disc. On this is incised both the azimuth-altitude reference system of the celestial meridians and parallels, as well as the main lines of the celestial vault: the celestial equator, the tropics, the ecliptic (there is obviously a separate tympanum drawn for every point of equal latitude). All these lines, which in the model of the cosmos are circular, as we have noted, are transformed in the stereographic projection on the "tympanum" into a corresponding number of circles. On the "tympanum" is placed the transparent disk of the "grid", also obtained by means of stereographic projection, which represents the position of the principle stars. Rotating around the north-south axis of the universe, every twenty four hours the stars return to occupy their initial positions, and it is clear that at any given time they occupy a specific position within the oriented reference system. And vice versa: from the position they occupy within the oriented reference system can be found the astronomical hour.

To observe the stars, the astrolabe is used both in a vertical position (in order to read the altitude) as well as a horizontal one (to read the azimuth, the angle the stars form with the direction north). Vertically the astrolabe is also used as a "quadrant of the circle" or as "geometric quadrant" depending on the markings on its reverse (Fig. 11 and Fig. 12). 14 

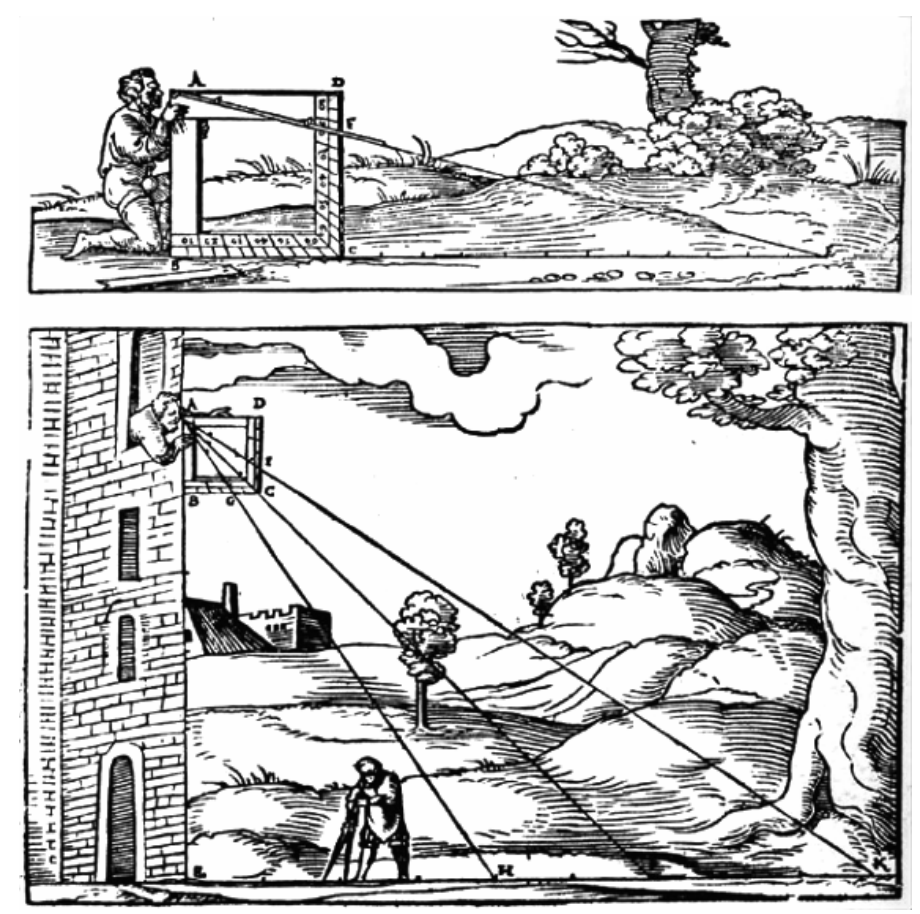

Fig. 11. W. Ryff (G. Rivius), 1547. Use of the geometric quadrant to determine distance

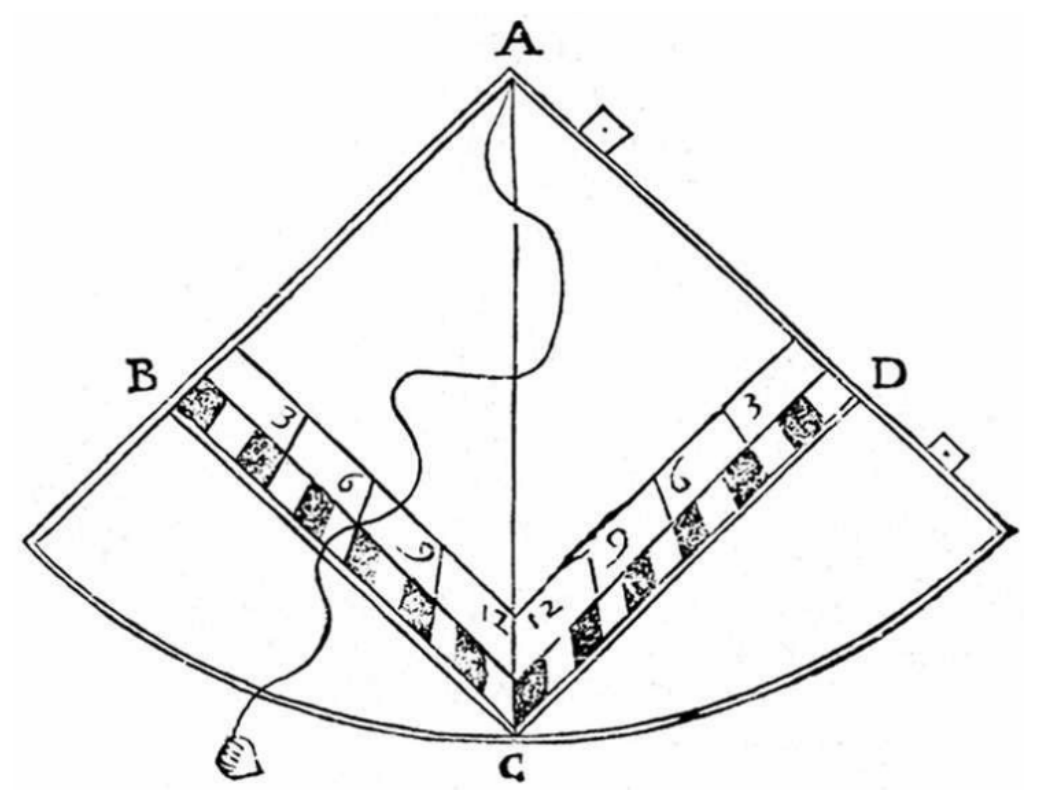

Fig. 12. Quadrant of the circle according to an illustration by Cosimo Bartoli, Venice 1614 
To represent the position of a star at a given time on the plane of the astrolabe it suffices to know the star's coordinates: the azimuth (the angle with respect to north, given by the meridian) and the altitude (the angle with the horizon represented by the parallel). One has only to imagine that from the centre of projection, the South Pole, there springs a pyramidal arrangement of rays that meet the stars, intersecting the equatorial plane (that, at an infinitely smaller scale, is represented by the plane of the astrolabe): once the coordinates of a star have been obtained, its image on the astrolabe is drawn as a crossing of its coordinates which are represented by the network of meridians and parallels already marked on the astrolabe.

Therefore, it can be readily seen that if its working principles are known, the astrolabe naturally suggests both the concept of projection and the construction of the perspective device (the astrolabe itself is a perspective device) and makes natural and intuitive the identification of the "point of view" and the "vanishing points", particularly the "centric point".

\section{Brunelleschi and the Astrolabe}

Having seen the working principles of stereographic projections in relation to the astrolabe, we shall now show how Brunelleschi in particular might have used this knowledge in setting out the architecture of the Trinità in S. Maria Novella.

Firstly we shall consider how the representation on a plane (on a painting) of "earthly things" is not very different from the representation of the stars on the plane of the astrolabe. In fact, the method used to represent the constellations (by joining the stars together with imaginary lines) is very similar to the method of drawing "earthly things". The difference consists in the fact that these thing or objects, unless they are on the picture plane, will appear distorted, that is, smaller if they are further from the observer, and larger if they are closer to him. This is precisely because they are arranged differently on the plane of the earth, as opposed to the stars which instead are all at the same distance on the celestial sphere (but even the constellations are deformed when projected on the astrolabe's plane due to the changing altitude on the horizon). To know the image of these "things" it is enough to know the image of their profile which is formed by many points joined by lines (like the stars and constellations), that is, to find, point by point, the intersections of the rays of the visual pyramid with the picture plane and join them together. In that case for each point we must again, as for the stars, know two coordinates: the azimuth, which in this case is its position in plan, and the altitude, which is its position in section. In other words we must draw the things point by point "with the plan and section and by means of the intersection" 15 , which is exactly the method described by Brunelleschi's biographers, thereafter called the costruzione legittima. 

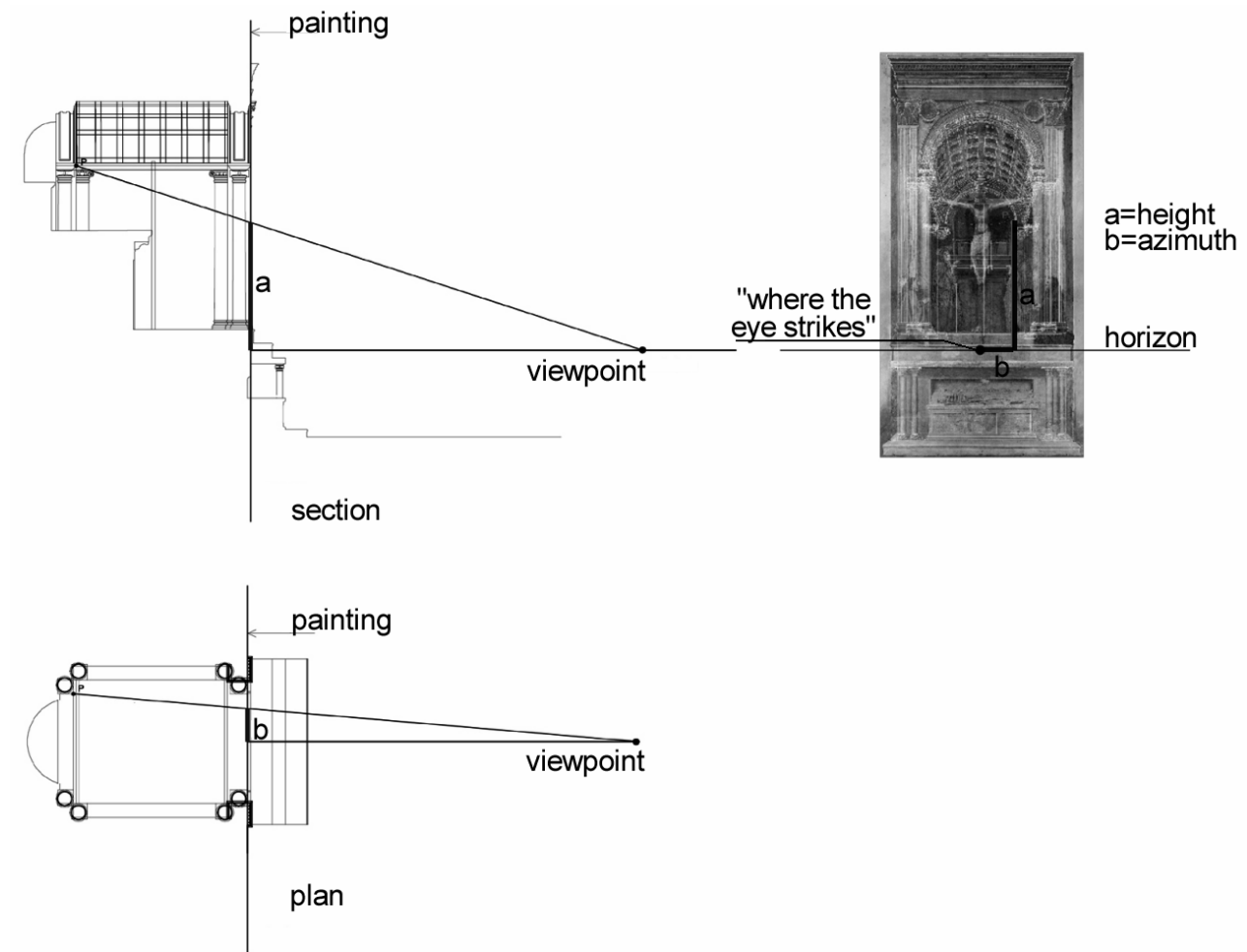

Fig. 13. Perspective construction for Masaccio's Trinità. Florence, Santa Maria Novella. Hypothetical plan and section and viewpoint [Sanpaolesi 1962]

Filippo, therefore, on the wall of the left aisle at the height of the third arch, probably with the aid of a cartoon, stretches a cord with a plumbline [cfr. Sampaolesi 1962: 51ff], as if he were drawing the north-south axis of the world (Fig.13). Next, he delineates the horizon line with a pair of compasses where the eye "strikes" the picture plane (at a height of three braccia), as if he were drawing the plane of the equator, and afterwards draws the "window" through which the scene is seen, as if it were the edge of an astrolabe held vertically. After having established the viewpoint (that is, the centre of projection), at a distance of about 10 braccia $^{16}$, he projects the distance points onto the wall (as if he were tracing the point of intersection of the maximum circle with the horizon line). $\mathrm{He}$ then draws a full-scale architrave and cornice resting on two Corinthian pilasters and the front of the vault held up by two columns crowned by Ionic capitals. Filippo now draws still at full scale, the profile of the chapel projected onto the picture plane (as if he were rotating the vault of the sky) and below, on the ground, he draws its plan (Fig. 13, plan). Finally, by joining every point with the projection centre, first in plan and then in section, he obtains for every point by intersection with the picture plane, the altitude on the horizon and the distance from the vertical axis of its image. He thus obtains by means of intersections, the distorted image of the vault over the crucified body of Christ. As in the astrolabe, where the image of the circles on the celestial vault remained circles, so too 
the arches of the terrestrial vault remain circular in the painting; and as in an astrolabe (if constructed with polar latitudes) the image of the meridians converges at the point where the eye "strikes", so in painting you will find the visual pyramid converges.

It remains to comment on the method, probably of a different sort, that Filippo had devised earlier to paint the panels of the Baptistery and of Piazza della Signoria (in order to be brief I will refer only to the first of the two, which is more complex because it is a specular image, though the reasoning regarding the second panel differs little). ${ }^{17}$ It is quite clear that in the case of the Baptistery it was not a question of drawing an imaginary scene, but of portraying a real one, for which Filippo thought of creating a macchina that would render that particular view, contrary to the case of the Trinità, which required the invention of a method of the illusionistic construction of an imaginary reality. Between these two cases lies the same difference that nowadays separates intuitive perspective taken directly from reality (which to some extent can be replaced by a photographic camera), and geometric perspective applied to the construction of invented images. How the macchina functions has been well known for a long time (Parronchi, 1958), but several hypotheses have been put forward regarding how the panel was drawn. The hypothesis, which essentially proposes the use of the costruzine legittima and which, for simplicity's sake, I shall refer to as Vagnetti's [Vagnetti 1979: 200], does not seem the most likely one because it does not form a specular image, whereas that panel required, as we have noted, the use of a mirror to view it properly. The hypothesis that the image was painted on the burnished silver [Gioseffi 1957-a; 1957-b], Brunelleschi drawing it, therefore, with his back to the Baptistery, is more probably correct and corresponds exactly to contemporary optical knowledge and the words of Filarete "He has a mirror (...) and he looks in it (...) and truly in this way I believe Pippo (...) discovered this perspective". 18 The image thus formed required another mirror to be seen the right way round and therefore accords perfectly with the apparatus described by the biographers. ${ }^{19}$ The hypothesis, in any case already excluded (Degli Innocenti, in [Battisti1976: 111]) that the panel was made of transparent glass such that it replaced the veil, must be discarded for the same reason as the first: because it does not result in an inverted image. It would do only for the Baptistery, taken to be symmetrical, but not for the column of St. Zenobius and the rest of the scene which, as Manetti writes, was represented in detail. 20

Another possible hypothesis is the suggestion by Fondelli [1977-b] , that Brunelleschi constructed a fully working camera obscura by making a hole in the main door of $S$. Maria del Fiore, and had therefore painted an image which was both in reverse and upside down.

In any case, Fondelli always points out, the perspective machine as interpreted by Parronchi evidences: the diminution of the image, its straightening, the reinstatement of the main distance, adjustment for clear image, the relationship of scale, and more, identifies the relationship between point of view, or centre of projection, and principal point: the former over the "hole", the latter in the centre of the image. It must be 
pointed out that these ideas correspond well with modern photogrammetric principles and above all with the principle of restitution by optical projection.

Each one of the hypotheses mentioned above, however, is founded not only on the principles of optics and the abacus, ${ }^{21}$ but also on the projective principles that are the basis of the workings of the astrolabe; this, therefore, can be considered as a further clue to support the idea that Filippo derived the origins of linear perspective from this instrument.

Translated from the Italian by David A. Vila Domini

\section{Notes}

1. This text constitutes a complete revision with several additions, amendments and arguments to support the thesis of my article "L'Astrolabio di Brunelleschi" [Jaff 1999], where I advanced the hypothesis that Brunelleschi deduced the theory of perspective from the workings of the astrolabe. That there may have been a connection between Ptolemaic projections and linear perspective was postulated by S.Y. Edgerton in several essays, starting with "Florentine interest in Ptolemaic Cartography..." [Edgerton 1974].

2. Even in the absence of reliable documentation critics are almost unanimous in attributing to Brunelleschi the authorship of the scheme for the chapel of the Trinità.

3. A reference to the subject addressed here is found in D. Woodward [Camerota 2001: note 3, p. 261, chap. X.2], where it is claimed that "The conceptual affinities between this construction [Ptolemy's third projection] and linear perspective are compelling but the historical connections must now be shown" ("Le affinità concettuali tra questa costruzione [quello della terza proiezione di Tolomeo] e la prospettiva lineare sono stringenti, ma i legami storici devono ancora essere dimostrati"). The definition of "stereographic projection" is due to Aquilonio (1613).

4. The debate on whether classical antiquity possessed a 'theory' of perspective, or at least knew of a rigorous rule by which to represent the three dimensions of space in paintings, murals or vases has gone on tenacioulsy for at least five centuries. Two are the main positions in this debate: that which argues that western antiquity developed a specific body of knowledge (see amongst these the many works by Decio Gioseffi); and the other, for which perspective is an artistic expression bound to the specific culture at a certain time, and not an objective representational method (see, for example, [Panofsky 1927].

5. "[R]ivocare in luce l'antica leggiadria dello stilo perduto e spento" [Bruni 1847: 53].

6. Thus according to Antonio di Tuccio Manetti in the Vita di Filippo di Ser Brunellesco) and Giorgio Vasari in his Le Vite dei più eccellenti pittori, scultori e architetti.

7. Cfr. [Vagnetti 1979: 196]. Vagnetti and several English-speaking academics have put forward the hypothesis that Brunelleschi may have known the works of Ptolemy.

8. For the classification of the various types of projection see for example [Traversi 1968].

9. For the relationship between Brunelleschi and Dal Pozzo Toscanelli see for example the Introduction to [Galluzzi 1996].

10. Vitruvius speaks very obscurely of this in book IX from chap. 4 to chap. 8 [1999: 113118].

11. On this point see the recent anthology of classical and historical texts on perspective edited by Rocco Sinisgalli [1994]. 
12. “[Ptolemy's Planisphaerium] is an explanation of the system of projection know as stereographic, by which points on the heavenly sphere are represented on the plane of the equator by projection from one point, the pole" [Heath 1981, 2: 292].

13. We see how this property can be proved by means of Euclidean geometry, which Brunelleschi certainly knew and used. Given the sphere $S f$ of centre $O$ and radius $R$ (represented in Fig. 9 in orthogonal projection); given the equatorial plane $e$, and taking $e$ as the picture plane; given also the pole $S$ taken as centre of projection for points belonging to the upper hemisphere; and plane $p$ which does not pass through $S$ (perpendicular to the plane of representation): the intersection of said plane $p$ with sphere $S f$ is a circle, shown in Fig. 9 as segment $\mathrm{AB}$. We wish to prove that $A^{\prime} B^{\prime}$, stereographic projection of $A B$ on the picture plane, is also circular. We note the similar triangles $S A$ ' $O$ and $S A N$. We can say that $\mathrm{S} A^{\prime} / S O=S N / S A$ and in other words that $S A^{\prime} / R=2 R / S A$, and that means that $S A{ }^{\prime} S A=2 R^{2}=$ constant (which is the fundamental property of this type of projection). Therefore also $S A x S A^{\prime}=S B X S B^{\prime}$ and hence $S A: S B=S B^{\prime}: S A^{\prime}$; therefore the triangles $S A^{\prime} B^{\prime}$ and $S A B$ are similar: consequently, since $A B$ is the image form of a circle, $A^{\prime} B^{\prime}$ is also. This is even more evident if we exchange the positions of the segments $S A$ and $S B$, and we replace $A$ in $A$ " and $B$ in $B$ "; it is as if we made a $180^{\circ}$ rotation of the cone of vertex $S$, and therefore $A$ "' $B$ "' still represents a circle belonging to the cone. But $A$ '” $B$ " is parallel to $A$ ' $B$ ' given the similarity between $S A^{\prime} B^{\prime}$ and $S B^{\prime \prime} A$ " and therefore $A^{\prime} B^{\prime}$ 'represents a circle as well. It is therefore very simple to construct the projection of circles on the surface of the sphere. And it becomes very easy to represent on the plane the reference system of meridians and parallels arranged on the sphere.

14. The 'geometric quadrant' and the 'quadrant of a circle' are two simple, slightly different instruments; one is square, the other the shape of a quarter of a circle. Relying on the use of the vertical and the alignment with an alidad, or revolving index for reading the graduation, they allow the measurement of angles formed between two directions. The distances to distant points are then determined through the use of proportion. The front of the astrolabe was incised in such a way that it could be used as one of these instruments when held vertically.

15. "con la pianta e proffilo e per via della intersegazione" [Vasari 1985: 329].

16. In the reconstruction by Sanpaolesi [1962] the distance from the viewpoint is drawn equal to about 10 braccia (the text, however, indicates a distance of about $10 \mathrm{ml}$ ); in that by $\mathrm{E}$. Battisti [1976], $8.942 \mathrm{ml}$; in that by J. V. Field [Camerota 2001], $6.85 \mathrm{ml}$; in that by Maria Teresa Bartoli [1997], $4.45 \mathrm{ml}$. These differences depend, above all, on the different hypothesis adopted with regard to the structure of the chapel. The author is currently undertaking further reconstructions of the chapel.

17. On this point see, amongst others, E. Battisti [1976: 102].

18. "Abbi uno specchio (...) e guarda in esso (...) e veramente da questo modo credo che Pippo (...) trovasse questa prospettiva" [Filarete 1973: $651 \mathrm{ff}]$.

19. It has recently been suggested that the use of mirrors may not have been unusual amongst so called Flemish Primitives. But there are no signs of this in the texts, other than in Filarete's Trattato di architecttura [1973] and Leon Battista Alberti’s Della pittura, where he writes "things taken from Nature are corrected with a mirror".

20. In Alberti's theory, put forward in his De pictura (1435), the veil is the rectangle where the image to be represented is formed (imagined as a transparent, reticulated window).

21. It is known that Brunelleschi as a young man attended the Florentine "scuola di abbaco" where, amongst other things, optics was taught. 


\section{References}

BARTOLI, MARIA TERESA. 1997. Le ragioni geometriche del segno architettonico. Florence.

BATTISTI, EugENIO. 1976. Filippo Brunelleschi. Milan.

Bruni, LeONARdo. 1847. Vita di Messer Francesco Petrarca, ed. Galletti. Florence.

Camerota, F. 2001. Nel segno di Masaccio: L'invenzione della prospettiva. Exhibition catalogue. Florence.

EdgerTON, S.Y. 1974. Florentine interest in Ptolemaic Cartography as Background for Renaissance Painting, Architecture and Discovery of America. Journal of the Society of Architectural Historians 30, 4 (December 1974).

Filarete (Antonio Averlino). 1973. Trattato di architettura. 1461 (?). Milan. (First ed. Vienna 1896).

FONDELLI, M. 1977-a. Le tecniche mensorie del XV secolo. Florence.

. 1977-b. I fondamenti della fotogrammetria nella prima esperienza prospettica di F. Brunelleschi. Bollettino degli Ingegneri 11.

Gioseffi, D. 1957-a. Perspectiva artificialis, spigolature e appunti per la storia della prospettiva. Trieste: Istituto di Storia dell'Arte Antica e Moderna.

1957-b. Complementi di Prospettiva. Critica d'Arte 24: 468-488.

Heath, Thomas. 1981. A History of Greek Mathematics. 3 vols. New York: Dover. (First published 1921).

GALluZZI, PAOLO. 1996. Gli ingegneri del Rinascimento da Brunelleschi a Leonardo da Vinci. Florence.

GARIN, E. 1964. L'Umanesimo italiano, 4th ed. Bari. (First published as Der italienische Humanismus, Bern: Francke Verlag, 1947; English ed. Italian Humanism: Philosophy and Civic Life in the Renaissance, trans. Peter Munz, Oxford: Basil Blackwell, 1965).

JAFF, MARCO. 1999. L'astrolabio del Brunelleschi. Firenze Architettura 1.99 dossier. Florence. http://www.unifi.it/unifi/progarch/fa/fa99112.pdf

PANOFSKY, ERWIN. 1927. Die Perspektive als 'symbolische Form'. Leipzig \& Berlin.

SAMPAOLESI, P. 1962. Brunelleschi. Milan.

SinISGALli, RocCO. 1994-. Domus perspectivae. Florence.

TraVERSI, C. 1968. Tecnica cartografica. Florence.

VAGNETTI, L. 1979. De naturali et artificiali perspectiva. Florence.

VASARI, GIORGIO. 1985. Le Vite dei più eccellenti pittori, scultori e architetti. Milan.

Vitruvius. 1999. Ten Books on Architecture. Ingrid Rowland and Thomas Howe, eds. Cambridge UK: Cambridge University Press.

\section{About the Author}

Marco Jaff is an associate professor in the faculty of Architecture at the University of Florence, where he teaches architectural surveying. He has published numerous papers on surveying, architectural drawing and territorial history. For some years now he has been studying the origins of linear perspective. In addition to his academic activities, he directs Jaff Associati, a studio active in architecture and urban design. 